\title{
Absence of Novel CYP4F2 and VKORCI Coding Region DNA Variants in Patients Requiring High Warfarin Doses
}

James K. Burmester, PhD; Richard L. Berg, MS; Ingrid Glurich, PhD; Steven H. Yale, MD; John R. Schmelzer, PhD; and Michael D. Caldwell, MD, PhD

\begin{abstract}
Objective: Warfarin is an FDA-approved oral anticoagulant for long-term prevention of thromboembolism. Substantial inter-individual variation in dosing requirements and the narrow therapeutic index of this widely-prescribed drug make safe initiation and dose stabilization challenging. Single nucleotide polymorphisms (SNPs) occurring in CYP2C9, VKORCI, and CYP4F2 genes are known to impact dose, and VKORCI and CYP4F2 polymorphisms are associated with higher therapeutic dose requirements in our cohort. However, the most advanced regression models using personal, clinical, and genetic factors to predict individual stable dose account for only $50 \%$ to $60 \%$ of the observed variability in stable theapeutic dose in Caucasians.
\end{abstract}

Design and Methods: In this study, we used DNA sequence analysis to determine whether additional variants in CYP4F2 and VKORCI gene coding regions contribute to variable dosing requirements among individuals for whom the actual dose was the highest relative to regression modelpredicted dose.

Results and Conclusions: No novel DNA variants in the coding regions of these genes were identified among subjects requiring high warfarin doses, suggesting that other factors yet to be defined contribute to variability in warfarin dose requirements in this subset of our cohort.

Keywords: VKORCI; CYP4F2; Warfarin; Pharmacogenetics

\begin{abstract}
A chronic prevention of thromboembolic events and stroke, it also ranks high among drugs that cause serious adverse events. $^{1,2}$ The narrow therapeutic index coupled with substantial inter-individual variability in warfarin dose requirement puts patients at increased risk for hemorrhagic events, and the variability in dose requirements has been attributed to inter-individual differences in medical, personal, and genetic factors. Some factors known to contribute to this variability include valve replacement, diabetes, body surface area (BSA), age, and DNA variants in three enzymes whose
\end{abstract}

Corresponding Author: James K. Burmester, PhD; Center for Human Genetics; Marshfield Clinic Research Foundation; 1000 North Oak Avenue; Marshfield, WI 54449; Tel: 7I5-389-4368; Fax: 7I5-389-5757; Email: burmester.jim@mcrf.mfldclin.edu

activity impacts vitamin $\mathrm{K}$-dependent synthesis of coagulation factors: CYP2C9, VKORC1, and CYP4F2. ${ }^{3-7}$ Regression models that incorporate these factors have been developed to predict stable dose in order to improve clinical management (eg, time in thereapeutic range) and reduce thrombotic and hemorrhagic events. However, because these algorithms collectively explain only $50 \%$ to $60 \%$ of dose variability in Caucasians, ${ }^{8,9}$ efforts are continuing to identify additional genetic and clinical factors that systematically impact warfarin dose requirements.

Received: July 13,2010

Revised: April 21, 2011

Accepted: April 22, 20I

doi: $10.3121 / \mathrm{cmr} .2011 .951$
Financial Support: This research was supported through the Marshfield Clinic Research Foundation's Disease Specific Funds. 
Table 1. Warfarin dose (mg/week) prediction model.

\begin{tabular}{|c|c|c|c|}
\hline CYP2C9 Genotype & Variable ${ }^{\dagger}$ & $\begin{array}{l}\text { Regression Model } \\
\text { for Log(Dose) }\end{array}$ & Geometric Mean (Dose) \\
\hline \multicolumn{4}{|l|}{${ }^{*} 1 /{ }^{*} 1,{ }^{*} 1 /{ }^{*} 2,{ }^{*} 1 /{ }^{*} 3$} \\
\hline & Intercept & $4.004 \pm 0.177$ & \\
\hline & CYP2C9 & $-0.186 \pm 0.017$ & \\
\hline & VKORC1 & $-0.340 \pm 0.019$ & \\
\hline & VKORC1 Het & $0.069 \pm 0.025$ & \\
\hline & CYP4F2 & $0.111 \pm 0.018$ & \\
\hline & Male & $0.061 \pm 0.029$ & \\
\hline & Valve & $0.165 \pm 0.031$ & \\
\hline & Age $(y)$ & $-0.009 \pm-0.001$ & \\
\hline & $\mathrm{BSA}\left(\mathrm{m}^{2}\right)$ & $0.320 \pm 0.063$ & \\
\hline *2/*2 & & & 24.9 \\
\hline$\star 2 /{ }^{*} 3$ & & & 14.8 \\
\hline *3/*3 & & & 8.1 \\
\hline \multicolumn{4}{|c|}{ †Definition of regression model variables: } \\
\hline \multicolumn{4}{|c|}{ CYP2C9 code: 1 for ${ }^{*} 1 /{ }^{*} 1,2$ for ${ }^{*} 1 /{ }^{*} 2,3$ for ${ }^{*} 1 /{ }^{*} 3$} \\
\hline \multicolumn{4}{|c|}{ VKORC1 code: 1 for $C C, 2$ for heterozygote, 3 for $T T$} \\
\hline \multicolumn{4}{|c|}{ VKORC1 Het (heterozygote indicator): 1 for het, 0 other } \\
\hline \multicolumn{4}{|c|}{ CYP4F2 Genotype: 1 for CC, 2 for CT, 3 for TT } \\
\hline \multicolumn{4}{|c|}{ Male (gender indicator): 1 for Male, 0 for Female } \\
\hline Valve (valve replacement & for Yes, 0 for No & & \\
\hline
\end{tabular}

Genetic influence on warfarin dose requirement has been linked to the direct metabolic effect on warfarin metabolism and vitamin $\mathrm{K}$ biological pathways. The enzyme CYP2C9 metabolizes warfarin, and patients encoding CYP2C $9 * 2$ and *3 genetic variants have reduced enzymatic activity of about $12 \%$ and $5 \%$, respectively, as compared with the wild-type enzyme, leading to lower therapeutic warfarin dose requirements. The VKORC1 enzyme catalyzes the conversion of vitamin $\mathrm{K} 2,3$ epoxide to vitamin $\mathrm{K}$ hydroquinone, which is an essential cofactor for the gamma carboxylase that catalyzes gamma carboxylation of pro-coagulation factors to cause the synthesis of active coagulation factors. Individuals homozygous $\mathrm{T}$ for the single nucleotide polymorphism (SNP) in intron 1 of the VKORC1 gene (rs9934438) have a daily warfarin dose that is nearly $45 \%$ lower $(3.5 \mathrm{mg} / \mathrm{d})$ than that required by individuals who are homozygous $\mathrm{C}$ at this locus $(6.2 \mathrm{mg} / \mathrm{d}) .{ }^{10}$ Additional DNA variants in VKORC1 have been associated with warfarin resistance. ${ }^{11,12}$

Recently, metabolism of vitamin K by CYP4F2 was shown to measurably impact warfarin stable dose requirements. ${ }^{13,14}$ The DNA variant rs2108622 (Val433Met) results in decreased capacity for metabolism of vitamin $\mathrm{K}$, resulting in an increased stable dose requirement of up to $24 \%$ among patients encoding the variant. ${ }^{7}$

To test the hypothesis that some patients who required high doses of warfarin had novel variants of CYP4F2, we sequenced the coding region of CYP4F2 in 16 patients whose actual dose requirement showed the highest divergence from the therapeutic warfarin dose predicted by our best regression model. Similarly, since VKORC1 is directly targeted by warfarin, genetic variability in the coding region of this enzyme could impact warfarin dosing requirements if enzymatic function or expression is affected. To test the hypothesis that some subjects in our population with warfarin resistance had missense variants of VKORC1, we sequenced the coding region of the VKORC1 gene in 10 subjects whose actual dose requirement showed the highest divergence from the dose predicted by our model.

\section{Materials and Methods}

Warfarin Cohort

We recruited 460 Caucasian patients, as described previously, ${ }^{15}$ from a large multi-specialty clinic for ongoing warfarin pharmacogenetic studies. All studies were approved by the Institutional Review Board of Marshfield Clinic. Patients with underlying conditions that impact warfarin dose requirement, including cancer, renal or hepatic insufficiency, congestive heart failure, or prescription for long-acting barbiturates were excluded. Among patients included in this study, none were being treated with carbamazapine, phenytoin or rifampin - medications known to impact warfarin metabolism. One patient was treated with diltiazem hydrochloride a known inhibitor of CYP2C9. However, because this interaction would be expected to decrease warfarin dose, it was not considered problematic in our investigation of high dose subjects. Clinical, anticoagulationrelated, and pharmacological treatment data were abstracted from the electronic medical record. Blood samples were collected for DNA extraction. CYP2C9*2, CYP2C9*3, VKORC1 (position 6853 of GenBank sequence AY587020), and CYP4F2 (rs2108622) DNA variants were previously tested in these patients. ${ }^{7}$ CYP2C9 genotyping was performed using the CYP2C9 Mutation Detection Kit (Roche Diagnostics Corp, Basil, Switzerland). VKORC1 genotyping was done using a validated TaqMan assay (Applied Biosystems, Foster City, CA). CYP4F2 genotype was measured using 
Table 2. High dose subjects sequenced for CYP4F2.

\begin{tabular}{|c|c|c|c|c|c|c|c|c|c|}
\hline $\begin{array}{l}\text { Patient } \\
\text { Number }\end{array}$ & $\begin{array}{l}\text { Dose } \\
\text { (mg/wk) }\end{array}$ & $\begin{array}{l}\text { Residual } \\
\text { (log scale) }\end{array}$ & $\begin{array}{l}\text { Residual } \\
\text { (mg/wk) }\end{array}$ & Gender & $\begin{array}{l}\text { Age } \\
\text { (y) }\end{array}$ & $\begin{array}{l}\text { BSA } \\
\left(m^{2}\right)\end{array}$ & CYP2C9 & VKORC1 & CYP4F2 \\
\hline 1 & 65.0 & 0.54 & 27.1 & $\mathrm{M}$ & 59.2 & 2.12 & ${ }^{*} 1 /{ }^{*} 1$ & $\mathrm{G} / \mathrm{A}$ & CT \\
\hline 2 & 85.0 & 0.72 & 43.5 & $\mathrm{M}$ & 62.9 & 2.00 & ${ }^{*} 1 /{ }^{*} 1$ & $\mathrm{G} / \mathrm{A}$ & $\mathrm{CT}$ \\
\hline 3 & 35.0 & 0.60 & 15.8 & M & 79.7 & 2.09 & ${ }^{*} 1 /{ }^{*} 3$ & $\mathrm{G} / \mathrm{A}$ & $\mathrm{CC}$ \\
\hline 4 & 47.5 & 0.67 & 23.2 & $M$ & 88.1 & 1.96 & ${ }^{*} 1 /{ }^{*} 1$ & $\mathrm{~A} / \mathrm{A}$ & $\pi$ \\
\hline 5 & 45.0 & 0.68 & 22.3 & $\mathrm{~F}$ & 68.3 & 1.89 & ${ }^{*} 1 /{ }^{*} 2$ & $\mathrm{G} / \mathrm{A}$ & $\mathrm{CC}$ \\
\hline 6 & 26.0 & 0.56 & 11.2 & $\mathrm{~F}$ & 72.4 & 1.68 & ${ }^{\star} 2 /{ }^{*} 3$ & $\mathrm{G} / \mathrm{G}$ & $\mathrm{CC}$ \\
\hline 7 & 82.5 & 0.47 & 31.0 & M & 68.5 & 1.98 & ${ }^{*} 1 /{ }^{*} 1$ & $\mathrm{G} / \mathrm{G}$ & CT \\
\hline 8 & 92.5 & 0.32 & 25.4 & $\mathrm{M}$ & 52.1 & 2.00 & ${ }^{*} 1 /{ }^{* 1}$ & $\mathrm{G} / \mathrm{G}$ & $\pi$ \\
\hline 9 & 35.0 & 0.53 & 14.4 & $\mathrm{~F}$ & 72.4 & 1.71 & ${ }^{*} 1 /{ }^{*} 2$ & $G / A$ & $\mathrm{CC}$ \\
\hline 10 & 60.0 & 0.55 & 25.3 & M & 79.8 & 1.93 & ${ }^{*} 1 /{ }^{*} 1$ & $\mathrm{G} / \mathrm{G}$ & $\mathrm{CC}$ \\
\hline 11 & 62.5 & 0.37 & 19.1 & $\mathrm{~F}$ & 73.3 & 2.29 & ${ }^{*} 1 /{ }^{*} 1$ & $\mathrm{G} / \mathrm{G}$ & CT \\
\hline 12 & 60.0 & 0.59 & 26.8 & M & 82.3 & 1.85 & ${ }^{*} 1 /{ }^{*} 1$ & $\mathrm{G} / \mathrm{G}$ & $\mathrm{CC}$ \\
\hline 13 & 122.5 & 0.88 & 71.5 & M & 52.4 & 2.36 & ${ }^{*} 1 /{ }^{*} 1$ & $\mathrm{G} / \mathrm{G}$ & $\mathrm{CC}$ \\
\hline 14 & 60.0 & 0.50 & 23.6 & M & 81.1 & 2.11 & ${ }^{*} 1 /{ }^{*} 1$ & $\mathrm{G} / \mathrm{G}$ & $\mathrm{CC}$ \\
\hline 15 & 65.0 & 0.48 & 25.0 & M & 65.8 & 1.98 & ${ }^{*} 1 /{ }^{*} 1$ & $\mathrm{G} / \mathrm{G}$ & $\mathrm{CC}$ \\
\hline 16 & 57.5 & 0.45 & 21.0 & $\mathrm{~F}$ & 74.2 & 1.77 & ${ }^{*} 1 /{ }^{*} 1$ & $\mathrm{G} / \mathrm{G}$ & CT \\
\hline
\end{tabular}

the Targeted Human DMET 1.0 assay (Affymetrix, Santa Clara, CA).

Regression models to predict therapeutic warfarin dose for this study population have been developed using available data and updated each time a new informative variable was identified. The current best model as summarized in table 1 explains about $56 \%$ of the variation in warfarin dose requirement. ${ }^{7}$ Variables in the model include gender, age, and BSA, as well as CYP2C9, VKORC1, and CYP4F2 genotypes.

\section{Selection of High Dose Patients}

Closely following initial publication of VKORC1 as a gene affecting warfarin dose, but before the identification of CYP4F2 as a gene that affects warfarin dose, we selected 10 patients for VKORC1 sequencing. The actual warfarin dose for these patients demonstrated high positive-divergence from model-based predicted dose. At that time, our prediction model included BSA, gender, CYP2C9 genotype, valve replacement, diabetes, and target international normalized ratio (INR). Similarly, closely following discovery of CYP4F2 as a gene that impacts warfarin dose requirement, we selected 16 patients for CYP4F2 sequencing. These subjects were again selected based upon divergence from model-based predicted dose (considering both absolute deviation of observed minus predicted $\mathrm{mg}$ and/or the proportional deviation observed/predicted).

Seven patients were sequenced for both VKORC1 and CYP4F2, since they represented high dose patients in the model both before and after inclusion of CYP4F2. The characteristics of the index subjects sequenced for CYP4F2 and VKORC1 are reported in tables 2 and 3, respectively. The mean dose of warfarin in the entire cohort was $32.9 \mathrm{mg} /$ week; whereas, the mean dose of the 16 subjects sequenced for CYP4F2 who were the focus of this study was $62.6 \mathrm{mg} /$ week.

DNA Sequencing and Additional SNP Testing

Polymerase chain reaction (PCR) primers for CYP4F2 (table 4) and VKORC1 (table 5) were designed within the

Table 3. High dose subjects sequenced for VKORC1.

\begin{tabular}{|c|c|c|c|c|c|c|c|c|c|}
\hline $\begin{array}{l}\text { Patient } \\
\text { Number }\end{array}$ & $\begin{array}{c}\text { Dose } \\
\text { (mg/wk) }\end{array}$ & $\begin{array}{c}\text { Residual } \\
\text { (log scale) }\end{array}$ & $\begin{array}{l}\text { Residual } \\
\text { (mg/wk) }\end{array}$ & Gender & $\begin{array}{c}\text { Age } \\
\text { (y) }\end{array}$ & $\begin{array}{l}\text { BSA } \\
\left(m^{2}\right)\end{array}$ & CYP2C9 & VKORC1 & CYP4F2 \\
\hline 2 & 85.0 & 0.69 & 42.2 & $M$ & 62.9 & 2.00 & ${ }^{*} 1 /{ }^{*} 1$ & $\mathrm{G} / \mathrm{A}$ & CT \\
\hline 7 & 82.5 & 0.70 & 41.5 & $\mathrm{M}$ & 68.5 & 1.98 & ${ }^{*} 1 /{ }^{*} 1$ & $\mathrm{G} / \mathrm{G}$ & CT \\
\hline 10 & 60.0 & 0.66 & 29.1 & $M$ & 79.8 & 1.93 & ${ }^{*} 1 /{ }^{*} 1$ & $\mathrm{G} / \mathrm{G}$ & $\mathrm{CC}$ \\
\hline 11 & 62.5 & 0.62 & 28.7 & $\mathrm{~F}$ & 73.3 & 2.29 & ${ }^{*} 1 /{ }^{*} 1$ & $\mathrm{G} / \mathrm{G}$ & $\mathrm{CT}$ \\
\hline 12 & 60.0 & 0.77 & 32.2 & $M$ & 82.3 & 1.85 & ${ }^{*} 1 /{ }^{*} 1$ & $\mathrm{G} / \mathrm{G}$ & $\mathrm{CC}$ \\
\hline 13 & 122.5 & 1.03 & 78.8 & $M$ & 52.4 & 2.36 & ${ }^{*} 1 /{ }^{*} 1$ & $\mathrm{G} / \mathrm{G}$ & $\mathrm{CC}$ \\
\hline 14 & 60.0 & 0.68 & 29.5 & $\mathrm{M}$ & 81.1 & 2.11 & ${ }^{*} 1 /{ }^{*} 1$ & $\mathrm{G} / \mathrm{G}$ & $\mathrm{CC}$ \\
\hline 17 & 37.5 & 0.85 & 21.4 & $\mathrm{~F}$ & 83.2 & 1.66 & ${ }^{*} 1 /{ }^{*} 3$ & $\mathrm{G} / \mathrm{G}$ & CT \\
\hline 18 & 50.0 & 0.74 & 26.1 & $\mathrm{~F}$ & 73.3 & 1.62 & ${ }^{*} 1 /{ }^{*} 1$ & $\mathrm{G} / \mathrm{G}$ & $\mathrm{CC}$ \\
\hline 19 & 55.0 & 0.68 & 27.1 & $M$ & 85.1 & 1.93 & ${ }^{*} 1 /{ }^{*} 1$ & $\mathrm{G} / \mathrm{G}$ & $\pi$ \\
\hline
\end{tabular}


Table 4. PCR and sequencing primers for CYP4F2.

\begin{tabular}{llll}
\hline & PCR Primer 1 & PCR Primer 2 & Sequencing Primer(s) \\
\hline Promoter & GTG GGC CTT GGG CAG T & GAG AGT GAC TCT GAT CCT GTT TCT GAT & GAG AGT GAC TCT GAT CCT GTT TCT GAT \\
Exon 1 & GGA AAC CAC CCA TCC TCC A & CCA GGC TGC AGG GAT TGG & GGA AAC CAC CCA TCC TCC A \\
Exon 2 & CCC ACT CCC TAA GCC TCG & CCG TCC CTG CCT CTC CA & CCG TCC CTG CCT CTC CA \\
Exon 3 & CTG CAG GGC CCA CAC AG & GCA TCC CTT AGC CCA GTC AAG TA & CTG CAG GGC CCA CAC AG \\
Exons 4 \& 5 & GAG GAA ACC AAG GCT CAG TGA GA & TCT TGC TGG GAG CCT CCA & GAG GAA ACC AAG GCT CAG TGA GA \\
Exon 6 & CCC TGC TTA GTC CTC CCT CT & GTG CTC AAG GGA GCA AGG AG & GTG CTC AAG GGA GCA AGG AG \\
Exon 7 & ATG GCT CCC TAG TGC CCT CTT A & GGA TAC TCT GTT TAC TGA TAG GAG GTA GA & ATG GCT CCC TAG TGC CCT CTT A \\
Exons 8 \& 9 & AGC TTT TCC TCC CCT CCC C & TCT CAG ATT AGA CTC AAG AGC CCT T & AGC TT TCC TCC CCT CCC C \\
& & & and \\
Exons 10 \& 11 GAC AGA CAG TTG TGT GTG TCT TT & GCG ACT TTG TAA CAA TTC TTG TTA AAA & TCT CAG ATT AGA CTC AAG AGC CCT T \\
& & GTT TAT TTT & and \\
& & & GCG ACT TTG TAA CAA TTC TTG TTA AAA \\
Exon 12 & TGA GGG AAA GAG AGC TGG AAC TT & GTA TCC AAC ATC ACC TCC CTC A & GTT TAT TT \\
Exon 13 (a) & GCT AAT TCT TAC AAA GTG AGA CAA & AAG GAA TGA AGC AGT GAT CCC T & TGA GGG AAA GAG AGC TGG AAC TT \\
& AAC AC AC & & GCT AAT TCT TAC AAA GTG AGA CAA AAC \\
Exon 13 (b) & TCC CGG GAG GAA ACC CCA TA & GGC ACG GAT ACC CCC TTC TC & and \\
& & & AAG GAA TGA AGC AGT GAT CCC T \\
& & & TCC CGG GAG GAA ACC CCA TA \\
& & and \\
& & & GGC ACG GAT ACC CCC TTC TC
\end{tabular}

PCR, polymerase chain reaction.

intron regions of the genes to maximize specificity of the primers for the target genes while excluding homolog amplification. The primers amplified the coding region of the genes. Primers were screened against the human genome sequence in GenBank to ensure that they did not match other known sequences. During primer preparation for CYP4F2 amplification, special care was taken to ensure that the primers did not amplify the coding region of CYP4F3, since this coding sequence shares homology with CYP4F2. Sequencing of VKORC1 was based on AY587020, and sequencing of CYP4F2 was based on NT_011295.11. A Taqman assay (catalog \# C_15853367_10) was used to test rs2074900 (Applied Biosystems, Foster City, CA).

\section{Results}

No novel DNA variants within the coding region of VKORC1 or CYP4F2 were identified during sequencing. Ten previously known CYP4F2 SNPs were identified during the sequencing of the 16 samples. The minor allele frequency (MAF) of these SNPs based on data for Caucasians in dbSNP and the MAF calculated from our selected sample of high dose subjects is

Table 5. PCR and sequencing primers for VKORC1.

\begin{tabular}{ll}
\hline Primer & Sequence \\
\hline VKORC1 - 1F & ATCGCCGAGTCAGAGGGC \\
VKORC1 - 1R & AACGACCCCGCGAGCAGT \\
VKORC1 - 2F & AAATCACCTTTCTCGGGCA \\
VKORC1 - 2R & AGTTACCTCCCCACATCCC \\
VKORC1 - 3F & GCAGCTCCTGGCATCTAGGTAGTG \\
VKORC1 - 3R & ATCTAGGGCCTTCTAGGGACCCAGATAT \\
VKORC1 - 2F2* & AGGGCCCTTCAGCCTCTAACAGTACT \\
\hline PCR, polymerase chain reaction \\
*VKORC1-2F and VKORC1-2F2 were used in a primary PCR to amplify exon 2. \\
A second PCR was performed with VKORC1-2F and VKORC1-2R.
\end{tabular}

shown in table 6 . Also shown in table 6 is the location of these SNPs in the transcribed region of the gene. Of these, rs3093114 and rs3093105 were tested on the DMET panel. ${ }^{7}$ We have previously reported that these SNPs are in partial linkage disequilibrium with rs2108622 in the Marshfield cohort, with $\mathrm{r}^{2}$ values of 0.42 and 0.48 , respectively. Although these SNPs showed strong association with warfarin therapeutic dose, ${ }^{7}$ neither of them attained strength of association with warfarin dose approaching that of rs2108622.

Because of the difference in MAF for rs2074900 (table 6) among the 16 samples that were sequenced and the predicted MAF obtained from dbSNP ( 0.11 vs 0.48 , respectively), we tested rs2074900 on the entire Marshfield cohort using a Taqman assay. Analysis of the model residuals showed that rs2074900 does not add to dose prediction in a model that already includes CYP4F2 (rs2108622). Accordingly, only rs2108622 is included in the current Marshfield dosing model.

\section{Discussion}

Although many algorithms have been developed for predicting stable warfarin dose using personal, medical, and genetic factors, the best models available at this time only explain between $50 \%$ and $60 \%$ of the variability observed in therapeutic dosing requirement. While these models are superior to clinical data-only models that explain $18 \%$ to $20 \%$ of dose requirements, it is clear that much still remains to be discovered about warfarin drug-dose response. In this study, we focused on subjects that require a high dose in an effort to identify new potential genetic variants in CYP4F2 that impact on vitamin $\mathrm{K}$ availability, or VKORC1 that impact on vitamin K-dependent clotting factors. ${ }^{16}$

122 CYP4F2 \& VKORC1 DNA variants in patients on warfarin 
Table 6. CYP4F2 SNPs identified during sequencing.

\begin{tabular}{llll}
\hline SNP & MAF dbSNP & MAF High Dose & Location \\
\hline rs1272 & $0.18-0.25$ & 0.4 & 3' UTR \\
rs1126433 & 0.47 & 0.25 & ' UTR \\
rs2074900 & 0.48 & 0.11 & His343His \\
rs2108622 & $0.23-0.33$ & 0.34 & Val433Met \\
rs3093105 & 0.1 & 0.18 & Trp12Gly \\
rs3093114 & 0.11 & 0.1 & Ala85Ala \\
rs3093153 & $0.03-0.06$ & 0.08 & Gly185Val \\
rs3093200 & 0.08 & 0.09 & Leu519Met \\
rs3093203 & $0.337-0.48$ & 0.16 & 3' UTR \\
rs3093204 & 0.07 & 0.10 & 3' UTR \\
\hline
\end{tabular}

SNP, single-nucleotide polymorphism; MAF, minor allele frequency; 3' UTR, 3' untranslated region.

Very rare DNA variants in VKORC1 have been associated with high warfarin dose requirements, ${ }^{17-19}$ with a high frequency of VKORC1 DNA variants having been identified in some populations. For example, up to $15 \%$ of Ethiopian Jews carry the Asp36Tyr variant, ${ }^{19}$ which has been associated with higher warfarin dose requirements. Further, about 15\% of non-Jewish Ethiopians carry this variant, although the study did not attempt to correlate this variant and warfarin dose. ${ }^{20}$ In contrast, this variant was much less common in both African and Yemenite Jews. ${ }^{19}$ In the present study, sequencing the coding region of VKORC1 did not identify novel DNA variants that account for warfarin resistance in the Marshfield Cohort, which is predominately of German and Northern European ancestry.

Because the common Val433Met DNA variant (rs2018622) in CYP4F2 results in an increase in stable warfarin dose, we investigated the possibility that rare variants in the coding region of CYP4F2 may exist in patients that require a substantially higher warfarin dose than predicted by the current model. By selecting patients with the highest unexplained dose, we enriched the possibility of finding a rare variant. However, even in this enriched population we did not find any novel DNA variants localized to the coding region of $\mathrm{CYP} 4 \mathrm{~F} 2$, making it unlikely that rare variants of this gene contribute substantially to warfarin dose requirements in our population.

Zhang et $\mathrm{al}^{21}$ recently reported a marginally significant association $\left(\mathrm{P}_{\mathrm{C}}=0.03\right)$ between rs2189784 in CYP4F2 and time to therapeutic INR, consistent with the finding that CYP4F2 plays a role in vitamin $\mathrm{K}$ metabolism. However, they did not find a significant association between rs2108622 and stable warfarin dose or time to therapeutic INR . They also did not find any novel associations between SNPs in CYP4F2 and (1) INR $>4$ during the first week of warfarin therapy, (2) warfarin sensitivity, (3) warfarin resistance, (4) stable warfarin dose, (5) time to therapeutic INR, or (6) bleeding complications. The lack of consistent associations in their results are interesting, given that rs2189784 and rs2108622 are highly correlated through linkage disequilibrium $\left(\mathrm{D}^{\prime}=0.98\right)$. By contrast, Sagrieya et $\mathrm{al}^{14}$ reported that addition of rs2108622 genotype to the International Warfarin Pharmacogenetics Consortium algorithm increased the $\mathrm{R}^{2}$ for dosing variability by $4 \%$.
Although whole genome scans have verified the importance of the V433M variant in CYP4F2, these investigations have not identified additional common SNPs that significantly influence warfarin dose requirements. ${ }^{22-24}$ While this does not completely rule out the possibility that additional genetic factors affecting warfarin dose will be discovered, it does suggest that such DNA variants are likely to occur at a much lower frequency compared to SNPs that have a frequency of $1 \%$ or greater, and are more likely to affect fewer individuals, and will be more challenging and resource-intensive to identify. It also suggests that any such discoveries are more likely to contribute only modestly toward reducing the unexplained variation currently observed in the best population-based warfarin dosing models.

It remains probable that rare, highly penetrant DNA variants that individually influence warfarin dose may be found, and that these discoveries will be important mediating factors in warfarin therapy for affected individuals. Notably, Sagrieya et $\mathrm{al}^{14}$ recently reported that pooling of rare variants with common variants for CYP2C9 significantly increased the CYP2C9 $\mathrm{R}^{2}$ to $12 \%$, adding credence to the premise that rare variants may contribute to dosing variability. It is likely that additional genetic factors may lie in other biological pathways that indirectly impact warfarin metabolism, and their contribution to warfarin dosing variability remains to be defined.

In conclusion, our investigation of additional coding region variants in CYP4F2 and VKORC1, genes previously determined to systematically impact warfarin dose requirements, did not yield new positive findings despite our focus on a selected group of subjects that require a relatively high dose of warfarin. Further studies are required to identify factors contributing to residual unexplained variability in warfarin dose requirement in order to make warfarin therapy safer for these patients.

\section{Acknowledgements}

The authors thank the Marshfield Clinic Research Foundation's Office of Scientific Writing and Publication for editorial support in the preparation of this manuscript. 


\section{References}

1. Glurich I, Burmester JK, Caldwell MD. Understanding the pharmacogenetic approach to warfarin dosing. Heart Fail Rev 2010;15:239-248.

2. Horton JD, Bushwick BM. Warfarin therapy: evolving strategies in anticoagulation. Am Fam Physician 1999;59:635-646.

3. Limdi NA, Veenstra DL. Warfarin pharmacogenetics. Pharmacotherapy 2008;28:1084-1097.

4. Caldwell MD, Berg RL, Zhang KQ, Glurich I, Schmelzer JR, Yale SH, Vidaillet HJ, Burmester JK. Evaluation of genetic factors for warfarin dose prediction. Clin Med Res 2007; 5:8-16.

5. Aithal GP, Day CP, Kesteven PJ, Daly AK. Association of polymorphisms in the cytochrome P450 CYP2C9 with warfarin dose requirement and risk of bleeding complications. Lancet 1999;353:717-719.

6. Rieder MJ, Reiner AP, Gage BF, Nickerson DA, Eby CS, McLeod HL, Blough DK, Thummel KE, Veenstra DL, Rettie AE. Effect of VKORC1 haplotypes on transcriptional regulation and warfarin dose. N Engl J Med 2005; 352:2285-2293.

7. Caldwell MD, Awad T, Johnson JA, Gage BF, Falkowski M, Gardina P, Hubbard J, Turpaz Y, Langaee TY, Eby C, King CR, Brower A, Schmelzer JR, Glurich I, Vidaillet HJ, Yale SH, Qi Zhang K, Berg RL, Burmester JK. CYP4F2 genetic variant alters required warfarin dose. Blood 2008; 111:4106-4112.

8. International Warfarin Pharmacogenetics Consortium, Klein TE, Altman RB, Eriksson N, Gage BF, Kimmel SE, Lee MT, Limdi NA, Page D, Roden DM, Wagner MJ, Caldwell MD, Johnson JA. Estimation of warfarin dose with clinical and pharmacogenetic data. N Engl J Med 2009;360:753-764.

9. Daly AK. Pharmacogenomics of anticoagulants: steps toward personal dosage. Genome Med 2009;1:10.

10. D'Andrea G, D'Ambrosio RL, Di Perna P, Chetta M, Santacroce R, Brancaccio V, Grandone E, Margaglione M. A polymorphism in the VKORC1 gene is associated with an interindividual variability in the dose-anticoagulant effect of warfarin. Blood 2005;105:645-649.

11. Harrington DJ, Gorska R, Wheeler R, Davidson S, Murden S, Morse C, Shearer MJ, Mumford AD. Pharmacodynamic resistance to warfarin is associated with nucleotide substitutions in VKORC1. J Thromb Haemost 2008; 6:1663-1670

12. Harrington DJ, Underwood S, Morse C, Shearer MJ, Tuddenham EG, Mumford AD. Pharmacodynamic resistance to warfarin associated with a Val66Met substitution in vitamin $\mathrm{K}$ epoxide reductase complex subunit 1 . Thromb Haemost 2005;93:23-26.

13. McDonald MG, Rieder MJ, Nakano M, Hsia CK, Rettie AE. CYP4F2 is a vitamin K1 oxidase: An explanation for altered warfarin dose in carriers of the V433M variant. Mol Pharmacol 2009;75:1337-1346.

14. Sagrieya H, Berube C, Wen A, Ramakrishnan R, Mir A, Hamilton A, Altman RB. Extending and evaluating a warfarin dosing algorithm that includes CYP4F2 and pooled rare variants of CYP2C9. Pharmacogenet Genomics 2010; 20:407-413.

15. Hillman MA, Wilke RA, Caldwell MD, Berg RL, Glurich I, Burmester JK. Relative impact of covariates in prescribing warfarin according to CYP2C9 genotype. Pharmacogenetics 2004;14(8):539-547.

16. Wallin R, Hutson SM. Warfarin and the vitamin K-dependent gamma-carboxylation system. Trends Mol Med 2004; 10:299-302.

17. Ainle FN, Mumford A, Tallon E, McCarthy D, Murphy K. A vitamin $\mathrm{K}$ epoxide reductase complex subunit 1 mutation in an Irish patient with warfrin resistance. Ir J Med Sci 2008;177:159-161.
18. Wilms EB, Touw DJ, Conemans JM, Veldkamp R, Hermans M. A new VKORC1 allelic variant (p.Trp59Arg) in a patient with partial resistance to acenocoumarol and phenprocoumon. J Thromb Haemost 2008;6:1224-1226.

19. Loebstein R, Dvoskin I, Halkin H, Vecsler M, Lubetsky A, Rechavi G, Amariglio N, Cohen Y, Ken-Dror G, Almog S, Gak E. A coding VKORC1 Asp36Tyr polymorphism predisposes to warfarin resistance. Blood 2007; 109:2477-2480.

20. Aklillu E, Leong C, Loebstein R, Halkin H, Gak E. VKORC1 Asp36Tyr warfarin resistance marker is common in Ethiopean individuals. Blood 2008;111:3903-3904.

21. Zhang JE, Jorgensen AL, Alfirevic A, Williamson PR, Toh CH, Park BK, Pirmohamed M. Effects of CYP4F2 genetic polymorphisms and haplotypes on clinical outcomes in patients initiated on warfarin therapy. Pharmacogenet Genomics 2009;19:781-789.

22. Cooper GM, Johnson JA, Langaee TY, Feng H, Stanaway IB, Schwarz UI, Ritchie MD, Stein CM, Roden DM, Smith JD, Veenstra DL, Rettie AE, Rieder MJ. A genome-wide scan for common genetic variants with a large influence on warfarin maintenance dose. Blood 2008;112:1022-1027.

23. Teichert M, Eijgelsheim M, Rivadeneira F, Uitterlinden AG, van Schaik RH, Hofman A, De Smet PA, van Gelder T, Visser LE, Stricker BH. A genome-wide association study of acenocoumarol maintenance dosage. Hum Mol Genet 2009; 18:3758-3768.

24. Takeuchi F, McGinnis R, Bourgeois S, Barnes C, Eriksson N, Soranzo N, Whittaker P, Ranganath V, Kumanduri V, McLaren W, Holm L, Lindh J, Rane A, Wadelius M, Deloukas P. A genome-wide association study confirms VKORC1, CYP2C9, and CYP4F2 as principal genetic determinants of warfarin dose. PLoS Genet 2009;5:e1000433.

\section{Author Affiliations}

James K. Burmester, PhD*; Richard L. Berg, MSt; Ingrid Glurich, PhD ; Steven H. Yale, MD\$"; John R. Schmelzer, PhDs; Michael D. Caldwell, MD, PhD

${ }^{*}$ Center for Human Genetics, Marshfield Clinic Research Foundation, Marshfield, WI USA

'Department of Biomedical Informatics, Marshfield Clinic

Research Foundation, Marshfield, WI USA

HOffice of Scientific Writing and Publication, Marshfield

Clinic Research Foundation, Marshfield, WI USA

§Clinical Research Center, Marshfield Clinic Research

Foundation, Marshfield, WI USA

"Department of Internal Medicine, Marshfield Clinic, Marshfield, WI USA

"Department of Wound Healing, Marshfield Clinic, Marshfield, WI USA 